February 2005 - NREL/CP-520-37438

\title{
Relationship of Recombination Lifetime and Dark Current in Silicon p-n Junctions
}

R.K. Ahrenkiel, W. Metzger, M. Page, and R. Reedy

National Renewable Energy Laboratory

J. Luther and J. Dashdorj

Colorado School of Mines

Prepared for the $31^{\text {st }}$ IEEE Photovoltaics Specialists Conference and Exhibition

Lake Buena Vista, Florida January 3-7, 2005
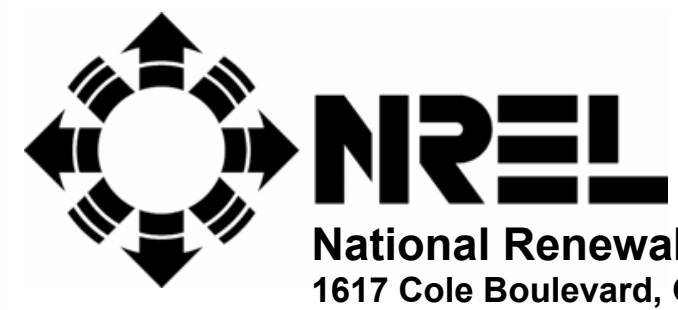

National Renewable Energy Laboratory 1617 Cole Boulevard, Golden, Colorado 80401-3393 303-275-3000 • www.nrel.gov

Operated for the U.S. Department of Energy

Office of Energy Efficiency and Renewable Energy

by Midwest Research Institute $\bullet$ Battelle 


\section{NOTICE}

The submitted manuscript has been offered by an employee of the Midwest Research Institute (MRI), a contractor of the US Government under Contract No. DE-AC36-99G010337. Accordingly, the US Government and MRI retain a nonexclusive royalty-free license to publish or reproduce the published form of this contribution, or allow others to do so, for US Government purposes.

This report was prepared as an account of work sponsored by an agency of the United States government. Neither the United States government nor any agency thereof, nor any of their employees, makes any warranty, express or implied, or assumes any legal liability or responsibility for the accuracy, completeness, or usefulness of any information, apparatus, product, or process disclosed, or represents that its use would not infringe privately owned rights. Reference herein to any specific commercial product, process, or service by trade name, trademark, manufacturer, or otherwise does not necessarily constitute or imply its endorsement, recommendation, or favoring by the United States government or any agency thereof. The views and opinions of authors expressed herein do not necessarily state or reflect those of the United States government or any agency thereof.

Available electronically at http://www.osti.gov/bridge

Available for a processing fee to U.S. Department of Energy and its contractors, in paper, from:

U.S. Department of Energy

Office of Scientific and Technical Information

P.O. Box 62

Oak Ridge, TN 37831-0062

phone: 865.576 .8401

fax: 865.576.5728

email: mailto:reports@adonis.osti.gov

Available for sale to the public, in paper, from:

U.S. Department of Commerce

National Technical Information Service

5285 Port Royal Road

Springfield, VA 22161

phone: 800.553 .6847

fax: 703.605.6900

email: orders@ntis.fedworld.gov

online ordering: http://www.ntis.gov/ordering.htm 


\title{
Relationship of Recombination Lifetime to Dark Current In Silicon p-n Junctions
}

\author{
Richard K Ahrenkiel, Wyatt K Metzger, Matthew Page, and Robert Reedy, National Renewable \\ Energy Laboratory, Golden, Colorado, and Joseph Luther and Jamiyana Dashdorj, Department of \\ Physics, Colorado School of Mines, Golden, Colorado
}

\begin{abstract}
Measurement of recombination and minoritycarrier lifetimes has become a central activity in photovoltaic technology. The primary measurement techniques for silicon technologies are based on photoconductive decay (PCD) and microwave reflectance (mPCD). The measurement of the correct recombination lifetime depends on the carriers being confined to a given spatial region of a diagnostic structure. The electric field of the PN junction separates the charges, and the measured decay time does not represent the real minority-carrier lifetime. In these cases, the measured quantity is a function of the true lifetime and the sample structure. Here, we examine these effects, both experimentally and theoretically, for the $n^{+}-p$ device structure common to terrestrial photovoltaics.
\end{abstract}

\section{INTRODUCTION}

In this work, we measured the recombination lifetime of some single crystal, p-type silicon wafers under a number of conditions. The lifetimes were measured by resonant coupled photoconductive decay (RCPCD). We first measured the lifetime of the wafers as received from the vendor, and then in a passivating solution of iodine methanol. The latter process usually produced a large lifetime increase as the surface recombination becomes negligible. Next, an $\mathrm{n}^{+}-\mathrm{p}$ junction was formed by phosphorous diffusion, and the lifetime was re-measured. The measured lifetime of the $n^{+}-p$ device always became larger than the bulk lifetime. From the asymptotic decay time, the dark current, $\mathrm{J}_{0}$, could be computed with recently developed theory $[1,2,3]$.

Secondary ion mass spectroscopy (SIMS) was used to measure the phosphorous profile after the $\mathrm{P}$-diffusion. The peak $\mathrm{P}$-concentration was about $1 \times 10^{19} \mathrm{~cm}^{-3}$ and the diffusion depth is $0.12 \mu \mathrm{m}$.

Open-circuit voltage decay has been analyzed by many authors $[4,5,6,7]$. Both device simulation theory and a simple analytical model of carrier recombination in a $p$-n junction device produced an increased carrier lifetime in the device. The latter model suggests that the measured lifetime in a $p-n$ device is a function of $J_{0}$. In other words, by measuring the photoconductive lifetime of the device, one can directly evaluate the dark current value of that device. The $\mathrm{n}^{+}$-layer was then removed by etching, and the bulk lifetime was re-measured. This procedure was followed to evaluate the parallel effects of phosphorous gettering during production, producing the lifetime increase in the junction device. The experimental results for a number of single crystal wafers will be presented and compared with theory.

\section{MEASUREMENT TECHNIQUE}

The PCD measurements were made using our RCPCD system [8]. The light source is a Coherent Infinity XPO optical parametric oscillator (OPO). The OPO was set up in the idler mode and is tunable from about $710 \mathrm{~nm}$ to about $2200 \mathrm{~nm}$. The pulse width is $5 \mathrm{~ns} F W H M$ and the pulse energy was controlled by the insertion of calibrated neutral density filters. The quantity measured by PCD is:

$$
\Delta \sigma(t)=q\left(\Delta n(t) \mu_{n}+\Delta p(t) \mu_{p}\right)
$$

Here, $\Delta \mathrm{n}(\mathrm{t})$ an $\Delta \mathrm{p}(\mathrm{t})$ are the excess carrier densities of electrons and holes, respectively.

Also, $\mu_{n}$ and $\mu_{p}$ are the minority-carrier mobilities of electrons and holes. We have shown in a previous paper that the long-term decay of excess majority carriers in a $p-n$ device is:

$\Delta n(t)=\Delta n_{0} \exp \left(\frac{-q J_{0} t}{K T C}\right)$

Here, $J_{0}$ is the reverse saturation current of the $\mathrm{p}-\mathrm{n}$ device, and $\mathrm{C}$ is the junction capacitance. This expression is applicable when the opencircuit voltage is less than the thermal voltage, $\mathrm{KT}$, or about $25 \mathrm{mV}$ at $300 \mathrm{~K}$. This time constant is commonly much larger than the recombination

lifetime that is a factor in $\mathrm{J}_{0}$. This equation assumes an ideality factor of unity. The physical source of the decay process is the discharge of 
the open-circuit voltage. The junction capacitance discharges through the forward-biased PN junction, and the discharge rate is inversely proportional to $\mathrm{J}_{0}$. The charge separation process occurs rapidly after the absorption of a light pulse. The first part of the process is the diffusion transit time to the junction. When a photon is absorbed at a distance $d$ from the junction, the diffusion transit time is approximately:

$$
\tau_{D}=d^{2} / \pi^{2} D
$$

Here $D$ is the minority-carrier diffusivity and $\tau_{D}$ is the transit time. For electrons generated in the base of the device, those located at a diffusion length or less, are collected by the junction. For a typical CZ silicon p-type wafer with a doping level of $1 \times 10^{15} \mathrm{~cm}^{-3}$, the computed diffusion transit time for electrons at one diffusion length is 9 ns. Thus, this process is very fast compared to typical silicon recombination times. More accurate calculations will be shown in the modeling section of this manuscript.

\section{EXPERIMENTAL RESULTS}

We will first show RCPCD measurements on a $10 \mathrm{ohm}-\mathrm{cm}$ p-type substrate prior to diffusion. The substrate was a standard quality, p-type commercial wafer grown by the $\mathrm{CZ}$ technique.

The data of curve A were obtained for the asreceived wafer. The low-injection lifetime here is about $11.6 \mu \mathrm{s}$. The data of curve B were obtained from the same wafer after cleaning in $\mathrm{HF}$ and immersion in an iodine/methanol solution. This process passivates the surface: ie., reduces [9] the surface recombination to very low values. The low-injection lifetime increased to about 48 $\mu$ s as a result of passivation.

The data of Fig. 2, curve B was produced by diffusing $n+$ regions onto both surfaces of the wafer of Fig. 1. The p-n junction that was formed dramatically changed the PCD. We attribute the large increase in PC lifetime to charge separation [3].

An alternative explanation for the lifetime increase (curve $B$ ) is that defects are removed (gettered) by the phosphorous diffusion. To check this hypothesis, the phosphorous layer was removed by etching and the lifetime was remeasured in air as shown in Figure 3, Curve B. Curve $A$ is the data from the virgin sample. We conclude, therefore, that impurity gettering is not a factor in the lifetime increase shown in Fig. 2, curve $B$, as the lifetime actually decreases after the $\mathrm{n}^{+}$removal.

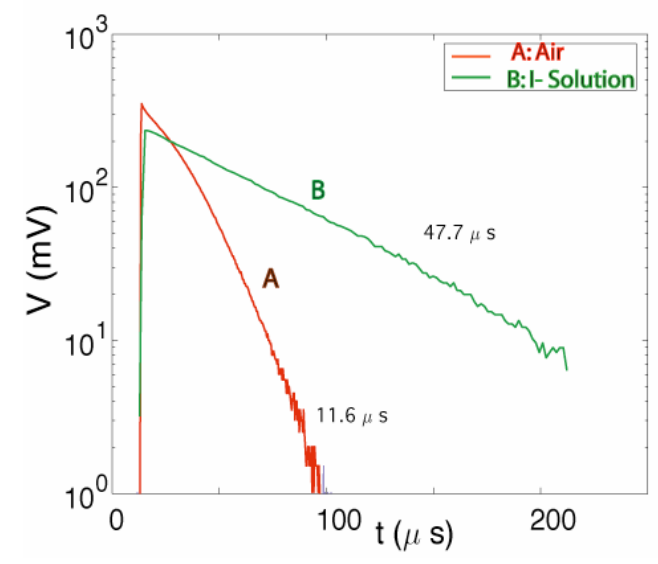

Fig. 1. Curve $A$ is the PCD decay of a p-type $C Z$ wafer in air environment. Curve $B$ is the PCD decay with the wafer immersed in iodine/ methanol solution. Prior to the latter process, the wafer was etched in HF.

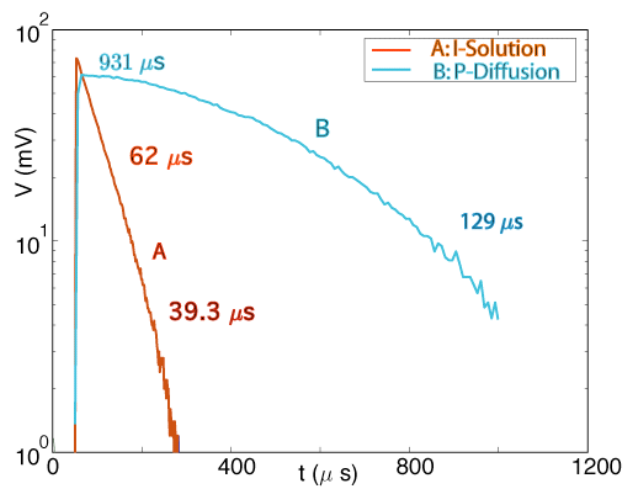

Fig. 2. The PCD decay of the wafer of Fig. 1 in iodine methanol solution (A). Curve $B$ is the $P C D$ measurement (in air) after $\mathrm{n}^{+}$diffusion.

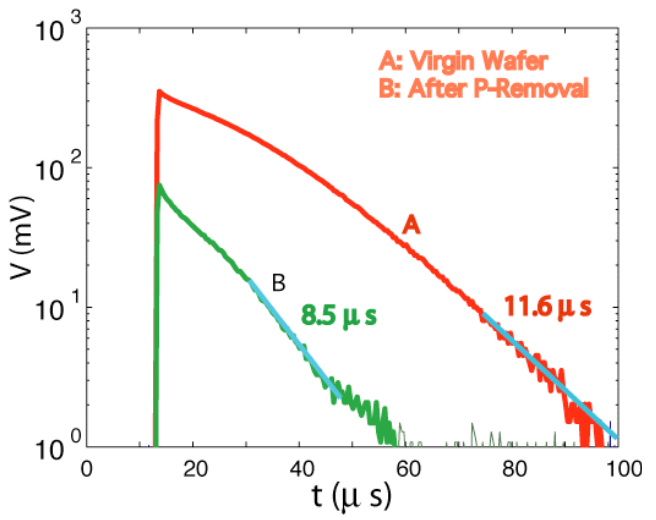

Fig. 3. The PCD decay in air ambient of the same $C Z$ wafer after etching of the $n+$ layer $(B)$. The decay of the virgin wafer is shown in curve (A). 
In summary, the charge separation effect described these results. The phosphorous diffusion and removal produced no net lifetime increase.

\section{DEVICE SIMULATION}

Fig. 4 shows the predicted response of the device of Fig. 2 using a commercial device simulation package. In each simulation, a 5 ns Gaussian laser pulse containing $2.7 \times 10^{10}$ photons $/ \mathrm{cm}^{2}$ injects carriers into either a wafer or an $n-p-n$ device structure that is $260 \mu \mathrm{m}$ thick. The simulated parameters include a base, $p$-type concentration of $2 \times 10^{14}$ holes $/ \mathrm{cm}^{3}$, and SRH electron and hole lifetimes of $50 \mu \mathrm{s}$ in the base. The n-regions have $1 \times 10^{19}$ electrons $/ \mathrm{cm}^{3}$, are $0.35 \mu \mathrm{m}$ thick, and are added to the front and back surfaces of the p-type base. Auger recombination is dominant in the n-region and calculated throughout the device with an Auger coefficient of $6.7 \times 10^{-32} \mathrm{~cm}^{6} / \mathrm{s}$. Mobility, as a function of impurity concentration, is calculated using standard values for silicon, and the model by Masetti et al [10]. The drift, diffusion, and recombination of excess carriers both during and after the laser pulse are tracked by simultaneously solving the hole and electron continuity equations and Poisson's equation using finite differences [10]. The photoconductivity signal, $\sigma_{p h}$, is calculated from the equation:

$$
\sigma_{p h}(t)=q \int_{V} d^{3} \mathbf{r}\left[\mu_{n}(\mathbf{r}, t) \Delta n(\mathbf{r}, t)+\mu_{p}(\mathbf{r}, t) \Delta p(\mathbf{r}, t)\right] .
$$

Curve A shows the calculated PC decay of a wafer with a passivated surface and a ShockleyRead-Hall lifetime of $50 \mu$ at low injection. The plots are presented in arbitrary units of the excess conductivity. Curve $B$ shows the calculated PC decay after the inclusion of an $n^{+}$ emitter into the model on both surfaces of the wafer.

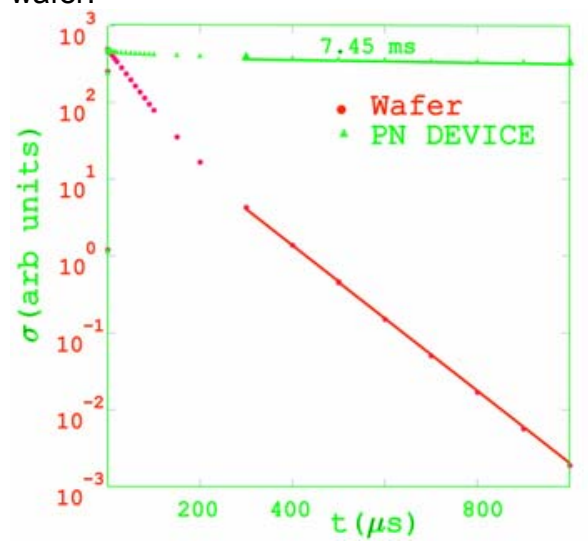

Fig. 4. The simulated decay curve of a bare, passivated wafer (curve A), and a wafer with $n^{+}$ regions on front and back surfaces (curve $B$ ).
The asymptotic lifetime of curve $A$ is just the lowinjection SRH value of $50 \mu \mathrm{s}$. For curve $B$, the excess hole concentration in the base becomes "flat" after about $10 \mu \mathrm{s}$, with a density of $8.6 \mathrm{x}$ $10^{11} \mathrm{~cm}^{-3}$. From the slope of the low-injection decay of the pn device, we calculate a decay time of about $7 \mathrm{~ms}$. This calculated decay time is appreciably larger than the measured values of Fig. 2. The simulated structure is an "ideal" device in the sense that all leakage currents originate from recombination. The calculated lifetime is expected to be larger than the experimental result. Other leakage sources add to the $J_{0}$ of a real device, including surface currents and shunt paths through the junction.

The data of Fig. 5 show the PCD decay of a wafer from another lot, doped p-type with a bulk carrier concentration varying between $2 \times 10^{15}$ to $1 \times 10^{16} \mathrm{~cm}^{-3}$. Four other wafers from this lot were similarly treated and the experimental results were nearly identical to those of Fig. 5 . The data of curve A comes from an as-received wafer measured in air ambient. The wafer underwent a standard phosphorous diffusion, followed by a HF etch and immersion in iodine methanol solution. The resulting PCD data is shown by curve $B$. The initial decay time is about $12 \mu$ followed by a much longer photoconductive "tail" as the lowest injection levels. The wafer was then removed from the solution, rinsed in DI water and dried. The PCD measurement produced the data of curve $\mathrm{C}$ with an initial decay time of about $17 \mu \mathrm{s}$. Thus, a slight increase in decay in air ambient indicates that the surface recombination effects are very small in these structures. These data suggest that the charge separation effects dominate the surface recombination in these $\mathrm{PN}$ structures. If one can generalize these results, then minimal improvements are made by front surface passivation in $\mathrm{N}^{+} P$ structures.

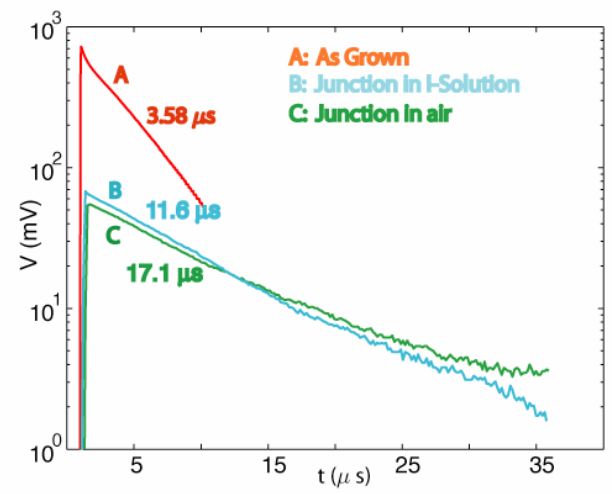

Fig. 5. The PCD decay of an as-received wafer (A) from another lot. Curve $B$ shows the PCD decay of the wafer after $\mathrm{n}^{+}$diffusion on front and back surfaces, and in an iodine methanol solution. Curve $\mathrm{C}$ shows the same wafer removed to air ambient. 


\section{PROPERTIES OF a $n^{+}-p$ DEVICE}

Using companion wafers from the same lot as that of Fig. 5, a small area solar cell was made from one-fourth of the two-inch wafer. The device had fairly poor characteristics, and the measured $J_{0}$ was $6.8 \mu \mathrm{A} / \mathrm{cm}^{2}$. The junction capacitance was measured, and $J_{0}$ was calculated from Eq. 2 to be $31 \mu \mathrm{A} / \mathrm{cm}^{2}$. At AM1.5 irradiance, the $\mathrm{Voc}$ was 0.45 volts and $\mathrm{J}_{\mathrm{sc}}$ was $24.7 \mathrm{~mA} / \mathrm{cm}^{2}$ with a total efficiency of $6.7 \%$.

Finally, $p-n$ mesa diodes were made by depositing metal contacts on the $\mathrm{n}^{+}$layer through a "shadow mask" on companion wafers. The $\mathrm{n}^{+}$ layer was then etched in unmasked areas, completing the fabrication of mesa diodes of three different sizes; varying from $250 \mu \mathrm{m}$ to 1.0 $\mathrm{mm}$. Dark I-V studies showed an increase in the dark current as the mesa diameter decreased. These behaviors are indicative of surface leakage a the mesa edge, with the latter dominating the bulk recombination processes.

The open-circuit voltage decay was measured by using a highly-attenuated, pulsed YAG laser source for excitation. The YAG wavelength was $1064 \mathrm{~nm}$, and the contacts to the mesa diode were connected to a fast, digitizing oscilloscope, using a 1 meg-ohm input. These data are shown in Fig. 6 and show a long-term decay time of 2.3 $\mu \mathrm{s}$. We compare this value to values of 12 to 17 us PCD decay time from Fig. 5. The shorter decay time here is accounted for by the surface leakage of the mesa diode. In summary, we suggest that the RCPCD decay time for a junction device may be equivalent to the open circuit voltage decay of a contacted device. Further work on larger area devices will test this hypothesis.

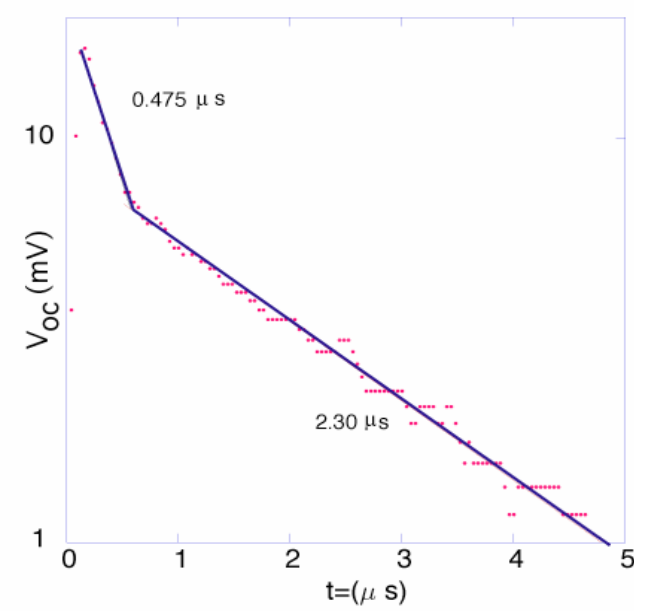

Fig. 6. The measured open-circuit voltage decay of small area mesa diodes fabricated on a companion wafer similar to that of Fig. 5 .

\section{CONCLUSIONS}

In this work, we have shown that a n+ junction on a p-type silicon wafer dramatically changes the photoconductive lifetime. The charge separation process produces a decay time that is representative of open-circuit voltage decay, and that it is not the recombination lifetime. However, such measurements is an indicator of the reverse saturation or dark current of the device.

\section{ACKNOWLEDGEMENT}

This work was supported by U.S. DOE Contract \# DE-AC36-99-G010337.

\section{REFERENCES}

1. R.K. Ahrenkiel, D. Friedman, W. K. Metzger, M. Page, and J. Dashdorj Mat. Res. Soc. Symp. Proc. Vol. 799, Z4.6.1 (2004).

2. Jamiyana Dashdorj' Richard Ahrenkiel, and Wyatt Metzger, Mat. Res. Soc. Symp. Proc. Vol. 799, Z4.5.1 (2004).

3. W. K. Metzger, R. K. Ahrenkiel, J. Dashdorj, and D. Friedman, Phys. Rev. B71, p. 035301, (2005).

4. F. A. Lindholm and C. T . Sah, J. Appl. Phys. 47, 4203 (1976).

5. S. R. Dhariwal, L. S. Kothari, and S. C. Jain, Solid-State Electronics 20, 297 (1977).

6. J. E. Mahan T. W. Ekstedt, R. I. Fran, and R. Kaplow, IEEE Transactions on Electron Devices, ED-26, 733 (1979).

7. R. Gopal. R. Dwivendi, and S. K. Srinvastava, J. Appl. Phys. 58, 3476 (1985).

8. R. K. Ahrenkiel and S. W. Johnston, Materials Science and Engineering B102, 161-172 (2003); 9. H. M'Saad, G. J. Norga, J. Michel, and L. C. Kimmerling, AIP Conference Proceedings V306, AIP Press, New York, 1994, p 471.

10. G. Masetti, M. Severi, and S. Solmi, IEEE Trans. On Electron Devices, ED-30, 764-769, (1983). 


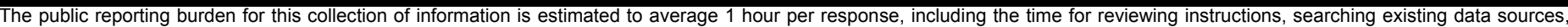

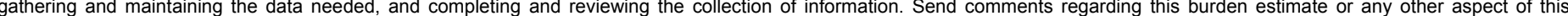

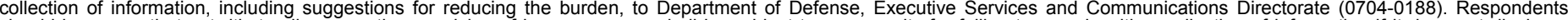

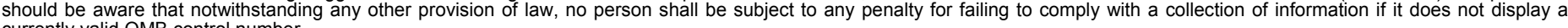
currently valid OMB control number.

PLEASE DO NOT RETURN YOUR FORM TO THE ABOVE ORGANIZATION.

\section{REPORT DATE (DD-MM-YYYY) \\ February 2005 \\ 2. REPORT TYPE \\ Conference Paper}

4. TITLE AND SUBTITLE

Relationship of Recombination Lifetime and Dark Current In Silicon

P-N Junctions

In Silicon

5a. CONTRACT NUMBER

DE-AC36-99-GO10337

5b. GRANT NUMBER

5c. PROGRAM ELEMENT NUMBER

5d. PROJECT NUMBER

NREL/CP-520-37438

5e. TASK NUMBER

PBA53101

7. PERFORMING ORGANIZATION NAME(S) AND ADDRESS(ES)

National Renewable Energy Laboratory

1617 Cole Blvd.

REPORT NUMBER

Golden, CO 80401-3393

NREL/CP-520-37438

9. SPONSORING/MONITORING AGENCY NAME(S) AND ADDRESS(ES)

10. SPONSOR/MONITOR'S ACRONYM(S)

NREL

11. SPONSORING/MONITORING AGENCY REPORT NUMBER

12. DISTRIBUTION AVAILABILITY STATEMENT

National Technical Information Service

U.S. Department of Commerce

5285 Port Royal Road

Springfield, VA 22161

\section{SUPPLEMENTARY NOTES}

\section{ABSTRACT (Maximum 200 Words)}

Measurement of recombination and minority-carrier lifetimes has become a central activity in photovoltaic technology. The primary measurement techniques for silicon technologies are based on photoconductive decay (PCD) and microwave reflectance (mPCD). The measurement of the correct recombination lifetime depends on the carriers being confined to a given spatial region of a diagnostic structure. The internal electric fields separate the charges, and the measured value does not represent the real minority-carrier lifetime. In these cases, the measured quantity is a function of the true lifetime and the sample structure. Here, we examine these effects, both experimentally and theoretically, for the $n+-p$ device structure common to terrestrial photovoltaics.

\section{SUBJECT TERMS}

PV; measurement of recombination; minority-carrier lifetimes; photoconductive decay (PCD); microwave reflectance (mPCD); silicon p-n junctions

\begin{tabular}{|c|c|c|c|}
\hline \multicolumn{3}{|c|}{ 16. SECURITY CLASSIFICATION OF: } & \multirow{2}{*}{$\begin{array}{l}\text { 17. LIMITATION } \\
\text { OF ABSTRACT } \\
\text { UL }\end{array}$} \\
\hline $\begin{array}{l}\text { a. REPORT } \\
\text { Unclassified }\end{array}$ & $\begin{array}{l}\text { b. ABSTRACT } \\
\text { Unclassified }\end{array}$ & $\begin{array}{l}\text { c. THIS PAGE } \\
\text { Unclassified }\end{array}$ & \\
\hline
\end{tabular}

18. NUMBER
OF PAGES

\begin{tabular}{l} 
19a. NAME OF RESPONSIBLE PERSON \\
\hline 19b. TELEPONE NUMBER (Include area code) \\
\hline
\end{tabular}

